\title{
Plasma levels of catecholamine metabolites and serum levels of brain-derived neurotorophic factor in smokers with schizophrenia treated with varenicline: A pilot study
}

\author{
Wakako Umene-Nakano $^{1}{ }^{*}$, Reiji Yoshimura ${ }^{1}$, Hikaru Hori ${ }^{1}$, Asuka Katsuki ${ }^{1}$, Kenji Hayashi ${ }^{1}$, \\ Chiharu Yoshii ${ }^{2}$, Atsuko Ikenouchi-Sugita ${ }^{1}$, Kiyokazu Atake ${ }^{1}$, Jun Nakamura ${ }^{1}$ \\ ${ }^{1}$ Department of Psychiatry, School of Medicine, University of Occupational and Environmental Health, Kitakyushu City, Japan \\ ${ }^{2}$ Department of Respiratory Medicine, Wakamatsu Hospital of University of Occupational and Environmental Health, Kitakyushu \\ City, Japan \\ Email: ${ }^{\text {wakako-u@med.uoeh-u.ac.jp }}$
}

Received 10 September 2012; revised 8 October 2012; accepted 17 October 2012

\begin{abstract}
Objective: The present study sought to determine changes in plasma levels of catecholamine metabolites and serum levels of brain-derived neurotorophic factor (BDNF) among smokers with schizophrenia who were treated with varenicline. Methods: We compared plasma homovanillic acid (HVA) and 3-methoxy-4-hydroxyphenylglycol (MHPG) levels and serum BDNF levels across 4 groups, divided as follows: smokers with schizophrenia (S-Sc), nonsmokers with schizophrenia (NS-Sc), smokers who were otherwise healthy (S-HC) and nonsmokers who were otherwise healthy (NS-HC). In addition, we also examined plasma HVA and MHPG levels and serum BDNF levels prior to study initiation (T0) and 8 weeks after varenicline treatment (T8) in the $\mathrm{S}-\mathrm{Sc}$ and $\mathrm{S}-\mathrm{HC}$ groups. Results: Plasma HVA levels in the S-Sc group at T0 were significantly higher than in the NS-Sc, $\mathrm{S}-\mathrm{HC}$ and NS-HC groups at the same time point (S-Sc at T0; 7.6 $\pm 1.6 \mathrm{ng} / \mathrm{mL}$, NS-Sc; $4.8 \pm 1.0 \mathrm{ng} / \mathrm{mL}, \mathrm{S}-\mathrm{HC}$; $4.3 \pm 0.9 \mathrm{ng} / \mathrm{mL}$, NS-HC; $3.4 \pm 1.4 \mathrm{ng} / \mathrm{mL}, \mathrm{p}<0.0001)$. Plasma MHPG levels in the S-Sc group at T0 were significantly higher than in the NS-Sc and S-HC groups; in addition, plasma MHPG levels in the NS-HC group were significantly higher than in the S-HC group (S-Sc at T0; $5.2 \pm 0.7 \mathrm{ng} / \mathrm{mL}$, NS-Sc; 2.8 $\pm 1.2 \mathrm{ng} / \mathrm{mL}$, S-HC; $1.9 \pm 0.8 \mathrm{ng} / \mathrm{mL}$, NS-HC; $3.6 \pm 1.3$ $\mathrm{ng} / \mathrm{mL}, \mathrm{p}<0.0002)$. Serum BDNF levels did not differ between the S-Sc and NS-Sc groups. In contrast, no difference in plasma HVA levels, plasma MHPG levels or serum BDNF levels was observed between T0 and T8. Conclusions: In conclusion, plasma levels of HVA and MHPG in the S-Sc group were significantly higher than in the NS-Sc group. Serum BDNF levels
\end{abstract}

${ }^{*}$ Corresponding author. did not differ between the S-Sc and NS-Sc groups. Plasma HVA and MHPG levels and serum BDNF levels did not change after treatment with varenicline.

Keywords: Schizophrenia; BDNF; HVA; MHPG; Varenicline; Smoking Cessation

\section{INTRODUCTION}

Rates of smoking among individuals with schizophrenia are high, and several studies have estimated that these rates are two- to five-fold higher than those of the general population [1]. In addition, individuals with schizophrenia are less likely to stop smoking than others groups of smokers [2]. This is of significance, as smoking has been identified as one of the single most important risk factors for medical disease and may result in elevated rates of mortality for individuals with schizophrenia. As a result, there are now consistent and urgent recommendations for smokers with schizophrenia to quit smoking to improve health outcomes [3].

Varenicline is a smoking cessation aid approved by the Food and Drug Administration that acts as a selective partial agonist at $\alpha 4 \beta 2$ nicotinic acetylcholine receptors (nAChR). It has been reported to be more effective than other treatments, including bupropion and nicotine replacement therapy [4]. However, its use has been hindered by recent case reports suggesting it may cause exacerbations of underlying psychiatric disease in patients [5]. Prospective controlled trials of varenicline for smoking cessation have been conducted. However, large studies of this medication in patients with schizophrenia have yet been published. Only one double-blind randomized pilot study has been reported [6]. Uncontrolled case reports and case series have reported inconsistent effects, with some reporting good efficacy and tolerability and even improvements in cognitive symptoms [7-9], 
while others have reported an increased in psychotic [10] and mood symptoms [11]. Thus, it is critical to identify reliable predictors of good response to varenicline to maximize its efficacy while simultaneously minimizing the possible adverse consequences of varenicline use.

Nicotine is known to increase striatal dopamine metabolism, as evidenced by modest increases in homovanillic acid (HVA) [12,13]. Quarta et al. [14] reported that local perfusion of nicotine into the striatum significantly increases the extracellular concentration of dopamine. Two primary mechanisms that may be involved in this effect of nicotine have been suggested. The first is that there may be direct stimulation of dopamine release by activation of the non-alpha $7 \mathrm{nAChR}$, which is localized at dopaminergic terminals, and the second is that there may be stimulation of dopamine release as a result of glutamate release by activation of the $7 \mathrm{nAChR}$, which is localized at glutaminergic terminals. Rossi et al. [15] have reported that nicotine alone induces an increase in dopamine and its metabolites in all areas of the brain, an increase in cortical, and a global increase in 3-methoxy-4-hydroxyphenylglycol (MHPG), a major metabolite of noradrenaline. They found that the effects of nicotine and the mechanisms involved in its effects differed for different neurotransmitters and in different brain areas.

Brain-derived neurotrophic factor (BDNF), one of the most abundant neurotrophic factors in the brain, plays an important role in the development, regeneration, survival and maintenance of neurons [16]. Multiple lines of evidence suggest that BDNF modulates neurotransmission and neuronal adaptations in the ventral tegmental areanucleus accumbens pathway during the development of addiction, craving, and withdrawal [17]. Several studies specifically support the role of BDNF in nicotine addiction [18]. Recently, numerous studies have documented changes in BDNF levels in the blood of schizophrenic patients [19].

In a study exploring HVA, MHPG, and BDNF levels before and after 8 weeks of treatment with varenicline, we found that plasma HVA and MHPG levels in smokers were significantly higher than that in nonsmokers and that these levels did not change from baseline to 8 weeks after varenicline treatment in smokers [20]. In addition, serum BDNF levels in smokers were significantly lower than in nonsmokers; these levels did not change from baseline to 8 weeks after varenicline treatment among smokers [21].

It is well known that patients with schizophrenia ingest large amounts of caffeine [22,23]. However, there is very little data comparing plasma caffeine levels between smokers with schizophrenia and smokers who were otherwise healthy.

We hypothesized that plasma HVA and MHPG levels in smokers would be significantly higher than in nonsmokers and that serum BDNF levels in smokers would be lower than in nonsmokers among patients with schizophrenia. In addition, we hypothesized that plasma HVA and MHPG levels in smokers with schizophrenia would be significantly higher compared with both smokers and nonsmokers who were otherwise healthy. Finally, we hypothesized that serum BDNF levels in smokers with schizophrenia would be lower than in both smokers and nonsmokers who were otherwise healthy. To test this hypothesis, we investigated the association of plasma HVA, MHPG and BDNF levels in schizophrenic patients with nicotine dependence compared with schizophrenic patients who did not smoke. We also examined plasma HVA and MHPG levels and serum BDNF levels before and after varenicline treatment. Finally, we compared in plasma caffeine levels between smokers with schizophrenia and smokers who were otherwise healthy.

\section{METHODS}

\subsection{Setting and Subjects}

Between 2008 and 2011, 6 smokers with schizophrenia (S-Sc), 6 nonsmokers with schizophrenia (NS-Sc), 6 smokers who were otherwise healthy (S-HC) and 6 nonsmokers who were otherwise healthy (NS-HC) were recruited and assessed at the smoking cessation outpatient clinic at the University of Occupational and Environmental Health (UOEH) hospital. The protocol of this study was approved by the Ethics Committee at the UOEH. All subjects provided consent to participate after having been informed of the purpose of the study.

Eligibility criteria for the S-Sc group were as follows: 1) meeting DSM-IV TR criteria for schizophrenia and nicotine dependence, with scores greater than 5 on the Tobacco Dependence Screener Scale (TDS) being used to diagnose nicotine dependence [24]; 2) clinical stability as operationalized in the following manner: a) not having been hospitalized within 3 months of study initiation and b) having had no change in antipsychotic medication dosage within 4 weeks prior to assessment; 3 ) no current or past history of comorbid neurological disorder, significant medical conditions, abnormal results on laboratory screening tests, or additional substance use other than nicotine; and 4) treatment with varenicline or other smoking cessation aids during the 8 weeks of treatment.

Eligibility criteria for the NS-Sc were as follows: 1) no history of smoking; 2) met DSM-IV TR criteria for schizophrenia; 3) clinically stable as operationalized by a) not having been hospitalized within 3 months of study initiation and b) having had no change in antipsychotic medication dosage within 4 weeks prior to assessment; and 4) no current or past history of comorbid neurologycal disorder, significant medical conditions, abnormal results on laboratory screening tests, or addiction to alcohol or other substances. These groups were recruited to 
yield a nonsmoking group that did not differ from the smoking group with respect to age or sex distribution.

Eligibility criteria for the S-HC group were as follows: 1) meeting DSM-IV TR criteria for nicotine dependence, as assessed by a TDS score greater than 5; 2) did not meet any DSM-IV-TR psychiatric diagnosis; 3) did not have a current or past history of comorbid neurological disorder, significant medical conditions, abnormal results on laboratory screening tests, or addiction to alcohol or substances other than nicotine; and 4) treatment with varenicline or smoking cessation during the 8 weeks of treatment. These groups were recruited to yield a smoking control group that did not differ from the schizophrenia group with respect to age or sex distribution.

Eligibility criteria for the NS-HC group were as follows: 1) no history of smoking; 2) did not meet criteria for any DSM-IV-TR psychiatric diagnosis; and 3) no current or past history of comorbid neurological disorder, significant medical conditions, abnormal results on laboratory screening tests, or addiction to alcohol or substances. These groups were recruited to yield a nonsmoking control group that did not differ from the schizophrenia group with respect to age or sex distribution.

\subsection{Clinical Assessment}

The diagnoses were based on the results of the Structured Clinical Interview for DSM-IV Disorders (SCID-1) (First et al., 1995), and schizophrenic symptoms were rated using the Positive and Negative Syndrome Scale (PANSS; Kay et al., 1987) [25].

\subsection{Smoking Cessation Therapy}

As a part of the initial clinical evaluation, all of the smokers in the study were asked to complete baseline questionnaires to obtain demographic and smoking-related clinical data. The expiratory carbon monoxide $(\mathrm{CO})$ levels of the patients were measured using the Smokerlyzer system (Bedfont Scientific Ltd., Rochester, UK). Nicotine dependence levels were assessed using the Fagerström Test for Nicotine Dependence (FTND) [26].

The varenicline regimen used during the intervention was as follows: $0.5 \mathrm{mg}$ for 3 days, $1 \mathrm{mg}$ for 4 days, and 2 mg for 7 weeks. Drug treatments other than varenicline were maintained until the end of the study.

Abstinence from smoking was defined as a breath $\mathrm{CO}$ level below $7 \mathrm{ppm}$, and plasma cotinine concentrations were determined after 8 weeks.

\subsection{Measurement of the Blood Levels of HVA, MHPG, Cotinine, Caffeine and BDNF Levels}

Blood levels of HVA, MHPG, cotinine, caffeine and
BDNF for the S-Sc and S-HC groups were measured at baseline (T0) and 8 weeks after continuous treatment with varenicline (T8). Blood levels of HVA, MHPG and BDNF in the NS-Sc and NS-HC were measured only once. Fifteen milliliters of venous blood was drawn with the subjects in the supine position after having slept overnight. The blood was quickly separated in a centrifuge and stored at $-80^{\circ} \mathrm{C}$ until assayed.

The plasma concentrations of HVA and MHPG were analyzed using high-performance liquid chromatography with electrochemical detection (HPLC-ECD). Plasma HVA levels were analyzed using HPLC-ECD based on the method described by Yeung et al. [27] with slight modification, and plasma MHPG levels were also analyzed using HPLC-ECD based on the method described b Minegishi and Ishizaki [28]. The intra- and inter-assay coefficients of variation were $6 \%$ and $8 \%$, respectively. The recovery rate was more than $80 \%$.

Plasma concentrations of cotinine and caffeine were analyzed using high-performance liquid chromatography (HPLC) based on a slightly modified version described by Pacifici et al. [29]. In brief, plasma samples (500 mL) to which $100 \mathrm{~mL}$ of 7b-hydroxypropyltheophyline (16.7 $\mathrm{mg} / \mathrm{mL}$ ) were added as an internal standard were alkalized with $0.4 \mathrm{~mL}$ of $0.5 \mathrm{~N} \mathrm{NaOH}$ and subjected to solidphase extraction using Extrelut 1 (Merck, Darmstadt, Germany) cartridges. Extracts were eluted with $5 \mathrm{~mL}$ of dichloromethane. The organic phase was evaporated under $\mathrm{N} 2$, and the samples were redissolved in the mobile phase $\left(0.1 \%\right.$ acetic acid- $20 \mathrm{mM} \mathrm{KH_{2 }} \mathrm{PO}_{4}$-acetonitrile, 92:8) prior to injection into HPLC.

Serum BDNF levels were determined using the Duo Set ELISA Development System (DY248, R\&D Systems, Abingdon, UK). All assays were performed in duplicate by a trained operator using the buffers, diluents and substrates recommended by the manufacturer. The detection range of this assay was from 20 to $4000 \mathrm{pg} / \mathrm{mL}$. The intra- and inter-assay coefficients of variation were $5.2 \%$ and $9.6 \%$, respectively. The concentrations of the samples in each plate were calculated according to each standard curve and dilution factor.

\subsection{Statistical Analysis}

All statistical analyses were conducted using SAS version 9.1 (SAS Institute, Cary, North Carolina, USA). Plasma HVA and MHPG levels and serum BDNF levels for the 4 groups were analyzed using one-way analyses of variance (ANOVA). Chi-square tests and ANOVA were used to compare demographic data, and Tukey post-hoc tests were applied. The Wilcoxon sign rank test was used to compare plasma HVA and MHPG levels and serum BDNF levels at T0 with those measured at T8. The level of significance was set at $\mathrm{p}<0.05$. 


\section{RESULTS}

Demographic and clinical data and the tobacco use histories of the subjects are shown in Table 1. The mean $\mathrm{CO}$ levels at $\mathrm{T} 8$ in the $\mathrm{S}-\mathrm{Sc}$ and $\mathrm{S}-\mathrm{HC}$ groups were $2.2 \pm 1.3$ ppm and $1.8 \pm 2.2 \mathrm{ppm}$, respectively. The mean plasma cotinine levels at $\mathrm{T} 8$ in the $\mathrm{S}-\mathrm{Sc}$ and $\mathrm{S}-\mathrm{HC}$ groups were $0.0 \mathrm{ng} / \mathrm{mL}$ and $0.0 \mathrm{ng} / \mathrm{mL}$, respectively.

Plasma HVA levels in the S-Sc group at T0 were significantly higher than in the NS-Sc, S-HC and NS-HC groups at T0 (S-Sc at T0; $7.6 \pm 1.6 \mathrm{ng} / \mathrm{mL}, \mathrm{NS}-\mathrm{Sc} ; 4.8 \pm$ $1.0 \mathrm{ng} / \mathrm{ml}, \mathrm{S}-\mathrm{HC} ; 4.3 \pm 0.9 \mathrm{ng} / \mathrm{mL}$, NS-HC; $3.4 \pm 1.4$ $\mathrm{ng} / \mathrm{ml}, \mathrm{p}<0.0001)$. The plasma MHPG levels in S-Sc at T0 were significant higher than in NS-Sc and S-HC (S-Sc at T0; $5.2 \pm 0.7 \mathrm{ng} / \mathrm{mL}$, NS-Sc; $2.8 \pm 1.2 \mathrm{ng} / \mathrm{mL}$, $\mathrm{S}-\mathrm{HC} ; 1.9 \pm 0.8 \mathrm{ng} / \mathrm{mL}, \mathrm{NS}-\mathrm{HC} ; 3.6 \pm 1.3 \mathrm{ng} / \mathrm{mL}, \mathrm{p}<$ 0.0002) (Figure 1).

Plasma HVA and MHPG levels did not change between T0 and T8 for the S-Sc and S-HC groups (HVA of $\mathrm{S}-\mathrm{Sc} ; \mathrm{T} 0 ; 7.6 \pm 1.6 \mathrm{ng} / \mathrm{mL}, \mathrm{T} 8 ; 9.9 \pm 4.0 \mathrm{ng} / \mathrm{mL}, \mathrm{p}=$ 0.2188 , HVA of S-HC; T0; $4.3 \pm 0.9 \mathrm{ng} / \mathrm{mL}, \mathrm{T} 8 ; 4.3 \pm$ $1.2 \mathrm{ng} / \mathrm{mL}, \mathrm{p}=1.0000$, MHPG of S-Sc; T0; $5.2 \pm 0.7$ $\mathrm{ng} / \mathrm{mL}, \mathrm{T} 8 ; 6.1 \pm 3.5 \mathrm{ng} / \mathrm{mL}, \mathrm{p}=0.8125$, MHPG of $\mathrm{S}-\mathrm{HC} ; \mathrm{T} 0 ; 1.9 \pm 0.8 \mathrm{ng} / \mathrm{mL}, \mathrm{T} 8 ; 1.9 \pm 1.0 \mathrm{ng} / \mathrm{mL}, \mathrm{p}=$ 1.0000).

Serum BDNF levels were different among the 4 groups at T0 (S-Sc at T0; $5.9 \pm 4.8 \mathrm{ng} / \mathrm{mL}, \mathrm{NS}-\mathrm{Sc}$ at T0; $9.6 \pm 6.3 \mathrm{ng} / \mathrm{mL}, \mathrm{S}-\mathrm{HC}$ at T0; $5.4 \pm 2.2 \mathrm{ng} / \mathrm{mL}, \mathrm{NS}-\mathrm{Sc}$ at $\mathrm{T} 0 ; 16.1 \pm 10.6 \mathrm{ng} / \mathrm{mL}, \mathrm{p}=0.0433$ ), but there was not significant different between each 2 groups after posthoc analysis (Figure 2).

Serum BDNF levels did not change between T0 and T8 for the S-Sc and S-HC groups (BDNF of S-Sc; T0; $5.9 \pm 4.8 \mathrm{ng} / \mathrm{mL}, \mathrm{T} 8 ; 6.0 \pm 3.3 \mathrm{ng} / \mathrm{mL}, \mathrm{p}=0.8438, \mathrm{BDNF}$ of S-HC; T0; $5.4 \pm 2.2 \mathrm{ng} / \mathrm{mL}, \mathrm{T} 8 ; 4.8 \pm 2.4 \mathrm{ng} / \mathrm{mL}, \mathrm{p}=$ 0.4375).

Plasma caffeine levels did not change between $\mathrm{T} 0$ and T8 for either the S-Sc or S-HC groups (caffeine of S-Sc; T0; $4.1 \pm 3.0 \mathrm{~g} / \mathrm{mL}, \mathrm{T} 8 ; 3.5 \pm 2.5 \mu \mathrm{g} / \mathrm{mL}, \mathrm{p}=0.6250$, caffeine of S-HC; T0; $2.9 \pm 2.4 \mu \mathrm{g} / \mathrm{mL}, \mathrm{T} 8 ; 2.2 \pm 2.1$ $\mu \mathrm{g} / \mathrm{mL}, \mathrm{p}=0.4375)$.

No difference was observed between the PANSS score at T0 and T8 (PANSS-PP; T0; $18.5 \pm 1.5, \mathrm{~T} 8 ; 18.5 \pm 1.5$, $\mathrm{p}=1.0000$, PANSS-NP; T0; $24.8 \pm 2.6, \mathrm{~T} 8 ; 25.2 \pm 2.3, \mathrm{p}$ $=1.0000$, PANSS-GP; T0; $42.5 \pm 1.5$, T8; $42.5 \pm 0.8, \mathrm{p}=$ 1.0000 , PANSS total score; T0; $85.8 \pm 2.8, \mathrm{~T} 8 ; 86.2 \pm 1.7$, $\mathrm{p}=1.0000)$.

\section{DISCUSSION}

To the best of our knowledge, this is the first report to investigate the association of plasma MHPG and HVA

Table 1. Demographic, clinical characteristics, and tobacco use histories of the sample.

\begin{tabular}{|c|c|c|c|c|c|}
\hline & \multicolumn{2}{|c|}{ Schizophrenia } & \multicolumn{2}{|c|}{ Healthy controls } & \multirow[b]{2}{*}{$\mathrm{p}$} \\
\hline & $\begin{array}{c}\text { Smokers, } \\
\mathrm{S}-\mathrm{Sc}(\mathrm{N}=6)\end{array}$ & $\begin{array}{l}\text { Non-smokers, } \\
\text { NS-Sc }(\mathrm{N}=6)\end{array}$ & $\begin{array}{c}\text { Smokers, } \\
\text { S-HC }(\mathrm{N}=6)\end{array}$ & $\begin{array}{l}\text { Non-smokers, } \\
\text { NS-HC }(\mathrm{N}=6)\end{array}$ & \\
\hline Age (years) & $37.0 \pm 8.2$ & $36.8 \pm 8.3$ & $39.7 \pm 6.5$ & $37.3 \pm 7.3$ & 0.9092 \\
\hline $\mathrm{M} / \mathrm{F}(\mathrm{M} \%)$ & $3 / 3(50.0)$ & $2 / 4(33.3)$ & $4 / 2(66.7)$ & $4 / 2(66.7)$ & 0.6049 \\
\hline PANSS-PP & $18.5 \pm 1.5$ & $19.3 \pm 2.4$ & & & 0.6307 \\
\hline PANSS-NP & $24.8 \pm 2.6$ & $23.8 \pm 1.7$ & & & 0.5778 \\
\hline PANSS-GP & $42.5 \pm 0.8$ & $43.7 \pm 2.0$ & & & 0.3440 \\
\hline PANSS total score & $85.8 \pm 2.8$ & $86.8 \pm 3.3$ & & & 0.6362 \\
\hline Age of first use (years) & $23.0 \pm 8.3$ & & $19.8 \pm 1.6$ & & 0.9241 \\
\hline Duration of use (years) & $19.0 \pm 11.1$ & & $19.3 \pm 6.4$ & & 0.7449 \\
\hline Amount of use (cigarettes/day) & $25.3 \pm 9.9$ & & $29.2 \pm 9.2$ & & 0.5626 \\
\hline $\begin{array}{c}\text { Brinkman index (daily } \\
\text { number of cigarettes } \times \text { year) }\end{array}$ & $433.3 \pm 185.3$ & & $581.7 \pm 318.4$ & & 0.4696 \\
\hline $\begin{array}{l}\text { Frequency of smoking } \\
\text { cessation (times) }\end{array}$ & $1.0 \pm 1.3$ & & $1.0 \pm 0.9$ & & 0.9328 \\
\hline Scores of TDS & $8.0 \pm 2.6$ & & $8.0 \pm 2.7$ & & 1.0000 \\
\hline Scores of Fagerstrom test & $6.8 \pm 2.1$ & & $7.3 \pm 1.8$ & & 0.9348 \\
\hline CO levels (ppm) & $20.2 \pm 6.2$ & & $29.2 \pm 20.6$ & & 0.7444 \\
\hline Plasma cotinine level (ng/mL) & $174.2 \pm 38.9$ & & $233.8 \pm 20.7$ & & 0.5752 \\
\hline Plasma caffeine level $(\mu \mathrm{g} / \mathrm{mL})$ & $4.1 \pm 3.0$ & & $2.9 \pm 2.4$ & & 0.6304 \\
\hline
\end{tabular}




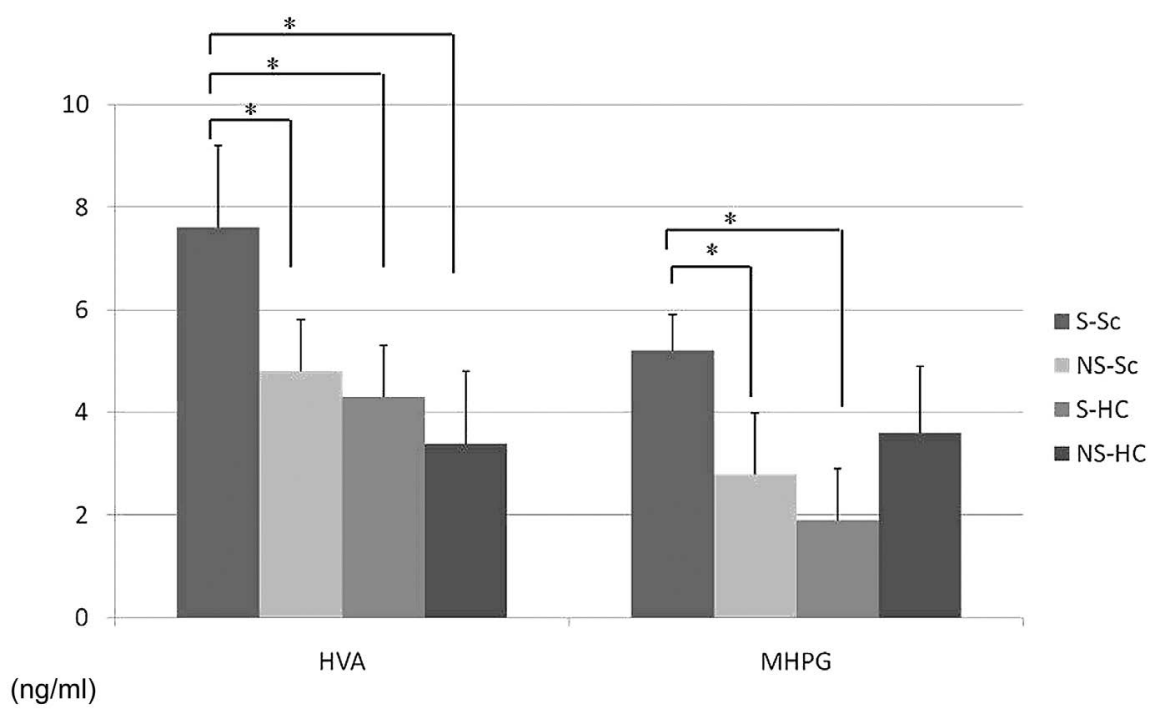

Figure 1. Differences in plasma HVA and MHPG levels between the 4 groups. Plasma HVA levels in the S-Sc group at T0 were significantly higher than that of the NS-Sc, S-HC, and NS-HC groups at T0 (S-Sc at T0; $7.6 \pm 1.6 \mathrm{ng} / \mathrm{mL}, \mathrm{NS}-\mathrm{Sc} ; 4.8 \pm 1.0 \mathrm{ng} / \mathrm{mL}, \mathrm{S}-\mathrm{HC} ; 4.3$ $\pm 0.9 \mathrm{ng} / \mathrm{mL}$, NS-HC; $3.4 \pm 1.4 \mathrm{ng} / \mathrm{mL}, \mathrm{p}<0.0001)$. Plasma MHPG levels in the S-Sc group at T0 were significantly higher than that of the NS-Sc and S-HC groups at T0 (S-Sc at T0; $5.2 \pm 0.7 \mathrm{ng} / \mathrm{ml}, \mathrm{NS}-\mathrm{Sc} ; 2.8 \pm 1.2 \mathrm{ng} / \mathrm{mL}, \mathrm{S}-\mathrm{HC} ; 1.9 \pm 0.8 \mathrm{ng} / \mathrm{mL}, \mathrm{NS}-\mathrm{HC} ; 3.6 \pm 1.3$ $\mathrm{ng} / \mathrm{mL}, \mathrm{p}<0.0002),{ }^{*} \mathrm{p}<0.05$.

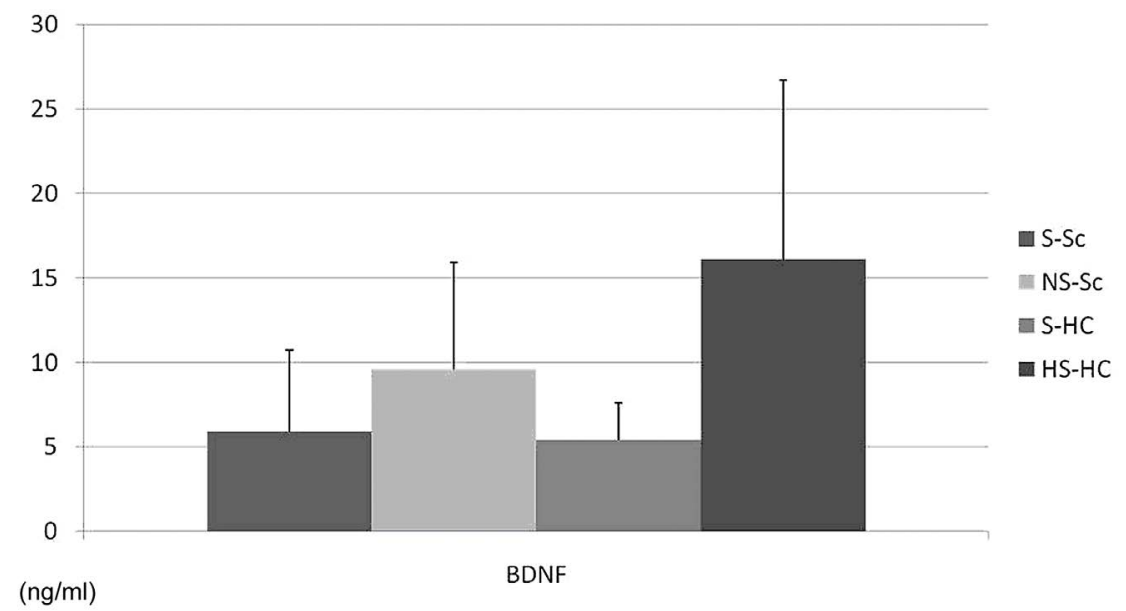

Figure 2. Differences in serum BDNF levels between the 4 groups. Serum BDNF levels differed between the 4 groups at T0 (S-Sc at T0; $5.9 \pm 4.8 \mathrm{ng} / \mathrm{mL}$, NS-Sc at T0; $9.6 \pm$ $6.3 \mathrm{ng} / \mathrm{mL}, \mathrm{S}-\mathrm{HC}$ at T0; $5.4 \pm 2.2 \mathrm{ng} / \mathrm{mL}, \mathrm{NS}-\mathrm{Sc}$ at T0; $16.1 \pm 10.6 \mathrm{ng} / \mathrm{mL}, \mathrm{p}=0.0433)$, but there was no statistically significant differences between each of the 2 groups after post-hoc analysis.

levels and serum BDNF levels after smoking cessation in patients with schizophrenia. The major finding of the present study was that plasma HVA and MHPG levels in the S-Sc group prior to varenicline treatment were significantly higher than in the NS-Sc and S-HC groups. However, 8 weeks of treatment with varenicline did not change plasma levels of catecholamine metabolites in the $\mathrm{S}-\mathrm{Sc}$ group. The findings of higher plasma catecholamine metabolites in normal smokers were partially consistent with the results obtained by Rossi et al. [15], who showed both increased dopaminergic and noradrenergic neurons in the brain. We have reported that plasma levels of MHPG were decreased in patients with early-stage schizophrenia and those in their first episode of schizophrenia [30]. These subjects included both smokers and nonsmokers. There have been no studies concerning changes in plasma HVA and MHPG levels in smoking and non-smoking schizophrenic patients. Nicotine might increase plasma HVA and MHPG levels during smoking in patients with schizophrenia. 
Varenicline, a partial $\alpha 4 \beta 2$ and full $\alpha 7$ nicotinic recaptor agonist, has been shown to inhibit nicotine self-administration and nicotine-induced increases in extracellular dopamine in the nucleus accumbens. Turner JR et al. [31] have reported that varenicline has been shown to be an efficacious smoking cessation aid, with a proposed mechanism of action that includes the modulation of dopamine release in reward areas of the brain. Their study also showed that varenicline elicits both anxiolytic effects in the marble-burying test and region- and timespecific receptor upregulation. Their findings suggest that receptor upregulation may be a mechanism underlying the efficacy of varenicline as a smoking cessation therapy.

In the present study, serum BDNF levels were not different between the S-Sc and NS-HC groups and did not change following treatment with varenicline. Zhang et al. [32] have reported that serum BDNF levels were significantly higher in smokers than nonsmokers $(\mathrm{p}<0.05)$. Higher BDNF levels have been correlated with fewer negative symptoms and with smoking more cigarettes. The finding of increased BDNF serum levels in smokers and higher BDNF levels with higher cigarette consumption are consistent with preclinical studies showing that nicotine induces BNDF and upregulates BDNF receptors in the rat brain [33]. Increased BDNF levels could offer some protection from the neurodegenerative processes that occur in schizophrenia, as a deficit in BDNF may contribute to the structural and functional brain alterations underlying the psychopathology of schizophrenia [34]. However, the origins of serum BDNF levels and their relationship to brain BDNF levels are not yet fully understood. Recent studies in normal humans have shown that there are lower plasma BDNF levels in smokers than nonsmokers and that plasma BDNF levels are increased after smoking cessation [35]. We have previously reported lower BDNF serum levels in smokers than nonsmokers [21]. However, an 8-week treatment with varenicline did not change serum BDNF levels in smokers. Possible explanations for this discrepancy may include differences in the pathological background of the patient's schizophrenia, varying ethnicities, biological heterogeneities or other factors. A critique of this minority of studies exploring BDNF blood levels in schizophrenic patients is that they did not adequately control for nicotine dependence. The differential effect of smoking on serum BDNF levels between patients and normal controls deserves further investigation as a potential means to understand the critical interactions of nicotine with the pathophysiology of schizophrenia.

In this study, varenicline was found to be safe and tolerable for patients. The results of this study support the efficacy of varenicline for individuals with schizophrenia, as observed in previous studies [36]. These findings are similar to those of Stapelton et al. [37], who found that in their mentally ill cohort, varenicline was well tolerated, did not exacerbate psychiatric symptoms and was more effective than nicotine replacement therapy.

We reconfirmed the several previous reports demonstrating larger amounts of caffeine consumption in smokers with schizophrenia when compared with healthy controls. However, no changes were found in plasma caffeine levels between $\mathrm{T} 0$ and $\mathrm{T} 8$. These results indicate that treatment with varenicline does not influence caffeine consumption in schizophrenic patients.

The present study was limited by the relatively small and heterogeneous sample and its design, which was an uncontrolled open-label study. In addition, blood samples were drawn only twice, before and after 8 weeks of varenicline treatment. As a result, the follow-up period after smoking cessation was very short. Future studies using larger samples and a stricter protocol for varenicline administration are needed to confirm our preliminary findings.

In conclusion, plasma HVA levels and plasma MHPG levels in the S-Sc group prior to varenicline treatment were significantly higher than those of the NS-Sc group. Serum BDNF levels were not different between the S-Sc and NS-Sc groups. Plasma HVA and MHPG levels and serum BDNF levels did not change after treatment with varenicline.

\section{REFERENCES}

[1] Bobes, J., Arango, C., Garcia-Garcia, M. and Rejas, J. (2010) Healthy lifestyle habits and 10-year cardiovascular risk in schizophrenia spectrum disorders: An analysis of the impact of smoking tobacco in the CLAMORS schizophrenia cohort. Schizophrenia Research, 119, 101109. doi:10.1016/j.schres.2010.02.1030

[2] Hughes, J.R. (1993) Possible effects of smoke-free inpatient units on psychiatric diagnosis and treatment. Journal of Clinical Psychiatry, 54, 109-114.

[3] Compton, M.T., Daumit, G.L. and Druss, B.G. (2006) Cigarette smoking and overweight/obesity among individuals with serious mental illnesses: A preventive perspective. Harvard Review of Psychiatry, 14, 212-222. doi:10.1080/10673220600889256

[4] Cahill, K., Stead, L.F. and Lancaster, T. (2008) Nicotine receptor partial agonists for smoking cessation. Cochrane Database Systematic Reviews, 3, Article ID: CD006103. doi:10.1002/14651858.CD006103.pub3

[5] Freedman, R. (2007) Exacerbation of schizophrenia by varenicline. American Journal of Psychiatry, 164, 1269. doi:10.1176/appi.ajp.2007.07020326

[6] Weiner, E., Buchholz, A., Coffay, A., Liu, F., McMahon, R.P., Buchanan, R.W. and Kelly, D.L. (2011) Varenicline for smoking cessation in people with schizophrenia: A double blind randomized pilot study. Schizophrenia 
Research, 129, 94-95. doi:10.1016/j.schres.2011.02.003

[7] Anghelescu, I. (2009) Successful smoking cessation and improvement of negative symptoms with varenicline in a stable schizophrenia patient. Journal of Neuropsychiatry and Clinical Neurosciences, 21, 102-103. doi:10.1176/appi.neuropsych.21.1.102

[8] Evins, A.E. and Goff, D.C. (2008) Varenicline treatment for smokers with schizophrenia: A case series. Journal of Clinical Psychiatry, 69, 1016. doi:10.4088/JCP.v69n0620a

[9] Fatemi, S.H. (2008) Varenicline efficacy and tolerability in a subject with schizophrenia. Schizophrenia Research, 103, 328-329. doi:10.1016/j.schres.2008.05.002

[10] Cinemre, B., Akdag, S.T., Metin, O. and Doganavsargil, O. (2010) Varenicline-induced Psychosis. CNS Spectrums, 15, 470-472.

[11] Alhatem, F. and Black, J.E. (2009) Varenicline-induced mania in a bipolar patient. Clinical Neuropharmacology, 32, 117-118. doi:10.1097/WNF.0b013e31816f75bc

[12] Yoshida, M., Yokoo, H., Tanaka, T., Mizoguchi, K., Emoto, H., Ishii, H. and Tanaka, M. (1993) Facilitatory modulation of mesolimbic dopamine neuronal activity by a mu-opioid agonist and nicotine as examined with in vivo microdialysis. Brain Research, 624, 277-280. doi:10.1016/0006-8993(93)90087-4

[13] Ishikawa, A. and Miyatake, T. (1993) Effects of smoking in patients with early-onset Parkinson's disease. Journal of the Neurological Science, 117, 28-32. doi:10.1016/0022-510X(93)90150-W

[14] Quarta, D., Ciruela, F., Patkar, K., Borycz, J., Solinas, M., Lluis, C. and Ferre, S. (2007) Heteromeric nicotinic acetylcholine-dopamine autoreceptor complexes modulate striatal dopamine release. Neuropsychopharmacology, 32, 35-42. doi:10.1038/sj.npp.1301103

[15] Rossi, S., Singer, S., Shearman, E., Sershen, H. and Lajtha, A. (2005) The effects of cholinergic and dopa- minergic antagonists on nicotine-induced cerebral neurotransmitter changes. Neurochemical Research, 30, 541558. doi:10.1007/s11064-005-2689-x

[16] Karege, F., Schwald, M. and Cisse, M. (2002) Postnatal developmental profile of brain-derived neurotrophic factor in rat brain and platelets. Neuroscience Letters, 328, 261-264. doi:10.1016/S0304-3940(02)00529-3

[17] Hall, F.S., Drgonova, J., Goeb, M. and Uhl, G.R. (2003) Reduced behavioral effects of cocaine in heterozygous brain-derived neurotrophic factor (BDNF) knockout mice. Neuropsychopharmacology, 28, 1485-1490. doi:10.1038/sj.npp.1300192

[18] Kenny, P.J., File, S.E. and Rattray, M. (2000) Acute nicotine decreases, and chronic nicotine increases the expression of brain-derived neurotrophic factor mRNA in rat hippocampus. Brain Research. Molecular Brain Research, 85, 234-238. doi:10.1016/S0169-328X(00)00246-1

[19] Ikeda, Y., Yahata, N., Ito, I., Nagano, M., Toyota, T., Yoshikawa, T. and Suzuki, H. (2008) Low serum levels of brain-derived neurotrophic factor and epidermal growth factor in patients with chronic schizophrenia.
Schizophrenia Research, 101, 58-66. doi:10.1016/j.schres.2008.01.017

[20] Umene-Nakano, W., Yoshimura, R., Yoshii, C., Hayashi, K., Ikenouchi-Sugita, A., Katsuki, A. and Nakamura, J. (2012) Plasma levels of metabolites of catecholamine in nicotine-dependent patients treated with varenicline. $\mathrm{Ni}$ cotine \& Tobacco Research, 14, 486-489. doi:10.1093/ntr/ntr149

[21] Umene-Nakano, W., Yoshimura, R., Yoshii, C., Hoshuyama, T., Hayashi, K., Hori, H. and Nakamura, J. (2010) Varenicline does not increase serum BDNF levels in patients with nicotine dependence. Human Psychopharmacolgy: Clinical and Experimental, 25, 276-279. doi:10.1002/hup.1113

[22] Strassnig, M., Brar, J. S. and Ganguli, R. (2006) Increased caffeine and nicotine consumption in community-dwelling patients with schizophrenia. Schizophrenia Research, 86, 269-275. doi:10.1016/j.schres.2006.05.013

[23] Rihs, M., Muller, C. and Baumann, P. (1996) Caffeine consumption in hospitalized psychiatric patients. European Archives of Psychiatry and Clinical Neuroscience, 246, 83-92. doi:10.1007/BF02274898

[24] Kawakami, N., Takatsuka, N., Inaba, S. and Shimizu, H. (1999) Development of a screening questionnaire for tobacco/nicotine dependence according to ICD-10, DSMIII-R, and DSM-IV. Addictive Behaviours, 24, 155-166. doi:10.1016/S0306-4603(98)00127-0

[25] Kay, S.R., Fiszbein, A. and Opler, L.A. (1987) The positive and negative syndrome scale (PANSS) for schizophrenia. Schizophrrnia Bulletin, 13, 261-276.

[26] Heatherton, T.F., Kozlowski, L.T., Frecker, R.C. and Fagerstrom, K.O. (1991) The fagerstrom test for nicotine dependence: A revision of the fagerstrom tolerance questionnaire. British Journal of Addiction, 86, 11191127. doi:10.1111/j.1360-0443.1991.tb01879.x

[27] Yeung, P.K., Buckley, S.J., Pedder, S.C. and Dingemanse, J. (1996) Determination of 3,4-dihydroxy-phenylacetic acid and 5-hydroxyindoleacetic acid in human plasma by a simple and rapid high-performance liquid chromatography assay. Journal of Pharmaceutical Sciences, 85, 451-453. doi:10.1111/j.1471-4159.1982.tb07897.x

[28] Minegishi, A. and Ishizaki, T. (1984) Determination of free 3-methoxy-4-hydroxyphenylglycol with several other monoamine metabolites in plasma by high-performance liquid chromatography with amperometric detection. Journal of Chromatography, 311, 51-57.

[29] Pacifici, R., Altieri, I., Gandini, L., Lenzi, A., Pichini, S., Rosa, M. and Dondero, F. (1993) Nicotine, cotinine, and trans-3-hydroxycotinine levels in seminal plasma of smokers: Effects on sperm parameters. Therapeutic Drug Monitoring, 15, 358-363. doi:10.1097/00007691-199310000-00002

[30] Hori, H., Yoshimura, R., Yamada, Y., Ikenouchi, A., Mitoma, M., Ida, Y. and Nakamura, J. (2007) Effects of olanzapine on plasma levels of catecholamine metabolites, cytokines, and brain-derived neurotrophic factor in schizophrenic patients. International Clinical Psychopharmacology, 22, 21-27. doi:10.1097/YIC.0b013e3280103593 
[31] Turner, J.R., Castellano, L.M. and Blendy, J.A. (2010) Parallel anxiolytic-like effects and upregulation of neuronal nicotinic acetylcholine receptors following chronic nicotine and varenicline. Nicotine \& Tobacco Research, 13, 41-46. doi:10.1093/ntr/ntq206

[32] Zhang, X.Y., Xiu, M.H., Chen da, C., Yang, F.D., Wu, G. Y., Lu, L. and Kosten, T.R. (2010) Nicotine dependence and serum BDNF levels in male patients with schizophrenia. Psychopharmacology, 212, 301-307. doi:10.1007/s00213-010-1956-y

[33] Maggio, R., Riva, M., Vaglini, F., Fornai, F., Molteni, R., Armogida, M. and Corsini, G.U. (1998) Nicotine prevents experimental parkinsonism in rodents and induces striatal increase of neurotrophic factors. Journal of $\mathrm{Neu}$ rochemistry, 71, 2439-2446. doi:10.1046/j.1471-4159.1998.71062439.x

[34] Shoval, G. and Weizman, A. (2005) The possible role of neurotrophins in the pathogenesis and therapy of schizophrenia. European Neuropsychopharmacology, 15, 319-

\section{9. doi:10.1016/j.euroneuro.2004.12.005}

[35] Kim, T.S., Kim, D.J., Lee, H. and Kim, Y.K. (2007) Increased plasma brain-derived neurotrophic factor levels in chronic smokers following unaided smoking cessation. Neuroscience Letters, 423, 53-57. doi:10.1016/j.neulet.2007.05.064

[36] Smith, R.C., Lindenmayer, J.P., Davis, J.M., Cornwell, J., Noth, K., Gupta, S. and Lajtha, A. (2009) Cognitive and antismoking effects of varenicline in patients with schizophrenia or schizoaffective disorder. Schizophrenia Research, 110, 149-155. doi:10.1016/j.schres.2009.02.001

[37] Stapleton, J.A., Watson, L., Spirling, L.I., Smith, R., Milbrandt, A., Ratcliffe, M. and Sutherland, G. (2008) Varenicline in the routine treatment of tobacco dependence: A pre-post comparison with nicotine replacement therapy and an evaluation in those with mental illness. Addiction, 103, 146-154.

doi:10.1111/j.1360-0443.2007.02083.x 